\title{
Menopause: a new beginning of happy years
}

\section{Mukesh Kumar*, Sunayana Singh}

Department of Zoology, M. S. J. Government P. G. College, Bharatpur, Rajasthan, India

Received: 16 January 2022

Revised: 13 February 2022

Accepted: 14 February 2022

\section{*Correspondence:}

Dr. Mukesh Kumar,

E-mail: prof.mukeshkumar@rediffmail.com

Copyright: (C) the author(s), publisher and licensee Medip Academy. This is an open-access article distributed under the terms of the Creative Commons Attribution Non-Commercial License, which permits unrestricted non-commercial use, distribution, and reproduction in any medium, provided the original work is properly cited.

\begin{abstract}
Menopause is an essential phase of women's life. Essentially, human female experiences different phases pertaining to the reproductive system and hormonal status these phases are prominently as follows. Childhood phases ( 0 to 12 year $)$

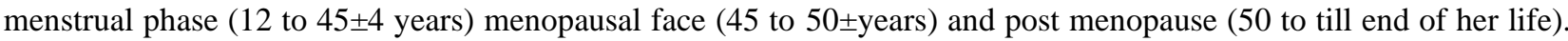
Menopause is complete cessation of menstrual cycle at least for a year. Menopausal phase causes many hormonal, physical, physiological, emotional and psychological changes in humans female. These changes are prominent in the reproductive system and hormonal profile. Menopausal state of women indicates the end of her reproductive period with other associated changes. Majority of women get disturbed physiologically, emotionally and psychologically. Menopausal woman develops the feeling of end of her sexual life and women hood. This paper reviews the state and perception of menopause, misconception regarding end of sexual life, better management of menopausal state and how menopause could be new the beginning of happier life physically, mentally, physiologically and sexually.
\end{abstract}

Keywords: Menopause, Symptoms, Better Management

\section{INTRODUCTION}

Reproductive phase (ability to get pregnant) of woman begins with the onset of menstrual cycle begins regularly (it is generally $15 \pm$ years age of girl to till her menopausal state). This period is characterized by different changes in the reproductive system which is referred as menstrual cycle. Ideally menstrual cycle is of $28 \pm 4$ days.

\section{Female reproductive system}

\section{Ovary}

Female reproductive system comprises of a pair of ovaries (left and right in abdominal region). These overies synthesize and release egg (ovum) and reproductive hormones (oestrogen and progesterone) which are controlled by the Luteinizing hormone and Follicle stimulating hormone ( $\mathrm{LH}$ and FSH) synthesized and secreted by anterior region of pituitary gland. At the time of female baby's birth, ovaries contain 3 to 4 million follicle (eggs) and their number decrease gradually. Maximum 400 to 450 are released during her entire reproductive phase and these eggs are released in the anterior region of fallopian tube with help of fimbriae (finger's like projections). Generally one egg (ovum) is released from a ovary monthly (menstrual cycle) in an alternate manner (from ovaries).

\section{Fallopian tubes}

Fallopian tubes are tubular structure which join ovaries anteriorly through Fimbriae and downwards to uterus. Fallopian tubes are the site where fertilization is taken place (if released egg meets sperm within 24 hours).

\section{Uterus}

Uterus is pear shaped structure where implantation takes place and entire embryo development is happened. 


\section{Cervix}

It is a lower part of uterus or canal which connects to the upper part of vagina, it is also referred as cervical canal. Cervical canal widens considerably in order to facilitate delivery of baby.

\section{Vagina}

Vagina is a muscular tissue which is connected at the cervix interiorly and opens outside to the woman's body. It receive penis during intercourse in order to facilitate the transport of sperm from male and menstrual discharge also comes out and also delivery of baby happen through vagina. Beside these external genitalia includes the mons pubis, labia majora, labia minora, clitoris and vestibules.

It is very important to discuss ovarian and menstrual period in normal fertile women. ${ }^{1,2}$

\section{THE OVARIAN CYCLE}

The ovarian cycle is controlled by hormones synthesized and secreted by the anterior region of pituitary gland namely FSH and LH. These hormones are controlled and regulated by the hypothalamus. Ovarian cycle is characterized by following important phases:

\section{Follicular phases}

Gonadotropin releasing hormone (GnRH) from hypothalamus stimulates the anterior region of pituitary to release FSH and LH. These hormones target ovaries (follicles) to mature these follicles in to almost 2-5 secondary follicles (they are few are in number). Enlargement of Follicles causes the release of oestrogen hormone.

\section{Ovulatory phase}

Out of these follicles, few follicles continue to mature and bulges out from the side of the ovary. Now LH is released in large amount which result in the rupturing of mature follicle and subsequently causes release of egg into the fallopian tube. This phenomenon is known as ovulation.

\section{Luteal phase}

As ovulation process gets over, the ruptured follicle converted in to yellow body which is referred as corpus luteum. This corpus luteum secrets progesterone (another important hormone) and oestrogen too. Both these two hormones (oestrogen and progesterone) send negative signals to anterior pituitary to supress the release of follicle stimulating hormone and luteinizing hormone. If pregnancy is not taken place, the corpus luteum abolishes and level of oestrogen and progesterone also decline sharply which in turn gradually enhance the increased of FSH and LH and ovary enters in to the next cycle. ${ }^{3-5}$

\section{MENSTRUAL CYCLE}

Menstrual cycle prepares uterus to lodge fertilized egg and subsequent embryonic development. If women doesn't get pregnant, the uterus wall (which is full of nutrients) breaks down in the form of menstrual bleeding or flow which comes out of vagina. This monthly bleeding is the sign of regular menstrual cyclicity (during pregnancy it stops). Estrogen and progesterone hormone play important role in menstrual cycle occurrence regularly. Estrogen is also important for female secondary sexual characters. Menstrual cycle is generally of $28 \pm 4$ days in normal women with following main phases. ${ }^{6,7}$

\section{Menstrual (1-5 days)}

Menstrual cycle beginning with this phase and characterized by rupturing of endometrium. Menstrual blood flow passes out of vagina and it lasts 4-5 days. It is infertile phase. Hormonal level (oestrogen and progesterone) are extremely low during this phase.

\section{Proliferative phase (5-14 days)}

Uterus wall is repaired under the influence of oestrogen hormone and causes the growth of endometrium for lodging the future embryos.

\section{Secretory phase (14-28 days)}

The phase causes the further growth of endometrium and full of nutrient (after ovulation) in order to provide food and healthy environment to embryo. If fertilization does not occur corpus luteum breaks down and endometrium disintegrates and enters into next cycle. ${ }^{8,9}$

\section{MENOPAUSE}

The literal meaning of menopause is complete cessation of menstrual cycle or in other words changes happening in her reproductive system (specially uterus and ovaries on monthly basis with help of hormones) are completely stopped but it is gradual process which begins during her forties of age group of a women. Menopause is not like 'switching off' mechanism. The cessation of menstruation is just one event during a long period of physical and physiological adjustment of female body, this state is called climactric. This climacteric state may last up to 20 years beginning from her age of forties. During this period (climacteric), oestrogen level of the female's body declines from the ovaries and production of eggs also diminish with various kind of changes physiologically and psychologically. ${ }^{10,11}$ Climacteric is a transition phase and it has following stages: (a) the pre menopause; (b) the perimenopause; and (c) the post menopause.

\section{The pre-menopause}

It is the period where women's menstrual cycle is regular and ovulation is still occurring. 


\section{The peri-menopause}

During this phase hormone level starts fluctuating and irregular menstrual cycle that continues for several years between pre menopause and menopause. The periods (menstrual blood flow) become lighter and intervals between menstrual cycle become shorter or longer or in other words 'irregular' which may be characterized by heavier bleeding. Sometimes stopes altogether This perimenopausal period is characterized by menopausal characters like hot flushes, dryness of vagina and other. ${ }^{12,13}$

\section{The post menopause}

This is the phase after menopause which remains until the end of woman's life. During her initial years of post menopause, woman continues to experience menopausal symptoms along with time new symptoms. ${ }^{14}$ The post menopausal period comprises of $1 / 3$ duration of woman's life.

\section{MECHANISM OF MENOPAUSE}

As it is well established that female reproductive system is controlled by hormone. These hormones are GnRH from hypothalamus, FSH, LH from anterior region of pituitary and Estrogen hormone (E) and Progesterone hormones (P) from ovaries. In general these hormone (GnRH, FSH, LH,
E, P) are responsible for puberty, menarche, initiation of menstrual cycle and occurrence of secondary sexual characters (directly or indirectly) in order to provide an opportunity (on monthly basis) to get pregnant (this also causes cyclic changes in ovary and uterus). As woman reaches in her forties (age), ovaries decline/stop providing egg which result in cessation of ovulation phenomenon and in turn corpus luteum does not form in ovaries. ${ }^{15}$

\section{HORMONAL STATUS DURING MENOPAUSE}

Oestrogen and progesterone level from ovaries also fall which raises the level of FSH and $\mathrm{LH}$ from anterior region of pituitary through negative feedback mechanism. The disturbance in release of hormone pattern causes the cessation of menstrual cyclicity and subsequently fertility. ${ }^{16}$

\section{MENOPAUSAL SYMPTOMS}

International studies show that following symptoms in a Table 1 have been recorded indifferent menopausal women from different region of the world. ${ }^{17,18}$ Apart from the above cited symptoms, some rare menopausal symptoms like tinnitus, electric shocks, gum disease, feeling of insects crawling on the skin, burning tongue, cold flushes, altered spatial awareness, body odour, have been reported. ${ }^{19-21}$

Table 1: menopausal symptoms.

\begin{tabular}{|c|c|c|}
\hline Menopausal (inclusive) symptoms & Common occurring symptoms & Emotional symptoms \\
\hline $\begin{array}{l}\text { Hot flushes (sudden emergence of heat from } \\
\text { neck to head region) which result in sweat } \\
\text { band. } \\
\text { - Irregular heart beat causes nervousness. } \\
\text { Development of habit of irritation over non- } \\
\text { issues. } \\
\text { Sudden mood swing and emotional } \\
\text { discharge in the form of tears. } \\
\text { - Sleepless nights, inadequate sleep along with } \\
\text { sweat. } \\
\text { Irregular periods are marked by heavy and } \\
\text { very heavy bleeding and sometimes scantly } \\
\text { spotting. } \\
\text { - Loss of sexual desire and sometimes hyper } \\
\text { libidinous (high sexual desire). } \\
\text { Fear of losing womanhood. } \\
\text { - State of tiredness usually. } \\
\text { Dryness of vagina. } \\
\text { - Worrisome nature. } \\
\text { - Sagging of breast. } \\
\text { Apprehensiveness. } \\
\text { Difficulties in maintaining concentration } \\
\text { and coordination. } \\
\text { - State of confusion. } \\
\text { Memory loss (partial). } \\
\text { Itchy and dryness in reproductive organs and } \\
\text { others. }\end{array}$ & $\begin{array}{l}\text { - Hot flushes and night } \\
\text { sweating. } \\
\text { - } \text { Vaginal dryness. } \\
\text { - Wrinkled skin and hair loss. } \\
\text { - Urinary infection. } \\
\text { - Weight gain }\end{array}$ & $\begin{array}{ll}\text { - } & \text { Feeling of anxiety. } \\
\text { - } & \text { Irritability. } \\
\text { - } & \text { Mepression. } \\
\text { - } & \text { Tearfulness lower } \\
& \text { self-esteem. } \\
\text { - } & \text { Conflict and } \\
& \text { arguments. }\end{array}$ \\
\hline
\end{tabular}




\section{HOLISTIC MANAGEMENT OF MENOPAUSE}

Menopause is not a disease or illness or disturbance, it is an essential phase (like puberty, menstruation) of woman's life. It can be managed by following different approaches(a) Hormone replacement therapy (HRT); (b) herbal and ayurvedic; (c) homeopathy; (d) acupuncture; (e) hydrotherapy; (f) aroma therapy; (g) meditation; (h) massaging; (i) yoga; (j) diet; and (k) exercise and healthy life style

\section{Hormone replacement theraphy (HRT)}

There are lot of controversy over hormone replacement therapy ${ }^{22}$ Some groups of researchers believe that it causes side effects in some menopausal women. ${ }^{23}$ While majority of scientist feel that HRT is completely safe and it has positive effects and relieve woman from menopausal associated effects. ${ }^{25}$ Some of the HRT recipient complain high BP \& migrain. ${ }^{24}$

\section{Herbal and ayurvedic approach}

Several herbal and plant based products are claimed to be beneficial in reducing the menopausal effects. ${ }^{26}$ Basically these products are estrogenic in nature and provide natural oestrogen which is beneficial to menopausal women with no side effects. ${ }^{27}$ But these products should be taken under medical guidance and should not be taken in excess. ${ }^{28}$ However efficacy, authenticity and dose regimen of these products in minimising the menopausal related effects yet to be established. ${ }^{29}$ But it is generally claimed that these products are free from side effects unlike HRT. ${ }^{30}$

\section{Homeopathic approach}

Practitioners of homeopathy opinion that menopausal symptoms are due to imbalance in the body ascribed to hormonal deficiencies. ${ }^{31}$ Calendula cream is claimed to reduce vaginal dryness. ${ }^{32}$ Homeopathic therapy should be taken under the guidance of qualified practitioner. However sufficient proof are needed pertaining to the effectiveness of this approach in minimising the menopausal related effects in women. ${ }^{33}$

\section{Acupuncture}

This is Chinese origin therapy. It is based on life force which moves in body along with invisible energy channel. If there are blockage in these energy channels, there will be physiological problems. Therapists of this approach facilitate a smooth flow of energy through these channels. Taker of this therapy felt that it is effective in relieving the menopausal effects. ${ }^{34}$ Adequate care should be taken while taking this therapy and one must ensure that the therapist should be well trained and properly qualified.

\section{Hydro or water therapy}

Hydrotherapy deals with water in base in treating the menopausal effects warm and cold water is used which enhances the blood circulation which in turn gives some kind of relief to the users. ${ }^{35}$

\section{Aroma therapy}

These are basically essential oils (concentrated form) extracted from leaves petals and some other parts of the plants. Essential oil should be used in a diluted form (otherwise they may cause allergic reaction to the body) with the base oil. ${ }^{36}$ These oil can be used for massaging or inhaled or few drops can be added in water bath. ${ }^{37}$ It is claimed that these oils develop good feeling and change of mood. ${ }^{38}$

\section{Massaging}

Massage is a generally used for enhancing the blood circulation and muscles toning. ${ }^{39}$ It is having positive effects on menopausal women. ${ }^{40}$

\section{Yoga}

Yoga is widely accepted for mental, physical and spiritual well-being of the human ${ }^{41}$ It includesvarious Asanas and inhalation of oxygen by deep breathing which target different organs systems of the body for achieving their effective and optimal functioning. Practicing of yoga by all age of people has shown good results. ${ }^{42}$

Now doctors strongly suggest adoption of yoga in daily life. Menopausal women also improve their quality of life by practicing yoga. It should be done under qualified yoga trainer. $^{42}$

\section{Meditation}

Meditation is a self-help technique. Under this process person empties his mind and tries to remove all negative thoughts. Initially it should be done under qualified trainer. Menopausal women certainly have very positive effects in mitigating effects of menopause. ${ }^{43}$

\section{Diet}

Variety of food recommended for menopausal women. Diet essentially includes iron, calcium, fibres, fruits therefore; one should have dairy products, fish with bones, broccoli, leafy and green seasonal vegetable in her daily life. Menopausal woman should drink plenty of water and she should avoids high fat food. Use of sugar and salt should be in her diet moderation. ${ }^{44}$

\section{Excercise}

Regular exercise can ease the transition by helping to relieve stress of menopausal women and enhance her quality of life, it is excellent way to reduce weight. Most healthy women should do150 minutes of moderate aerobic, 75 minutes of vigorous aerobic activity of a week. 
These activities may include walking, jogging, swimming etc. ${ }^{45}$

\section{IS MENOPAUSE END OF SEXUAL LIFE ???}

Does menopausal phase of women end her sexual life? Answer is big 'no'. Majority of menopausal women develop the feeling that their sexual life is over and their reproductive phase is over. They also feel that they are no longer attractive and losing the women hood. ${ }^{46}$ Their husbands do not take desired interest in them. ${ }^{47}$ Frequency of sexual intercourse is also decreased due to age of her partner (as man also goes through midlife sexual performance anxiety), her lake of corporation and dryness of vagina (sometimes it results in painful intercourse). In some cases women become religious and developed inhibition for active sex as their children are growing up. ${ }^{48}$ All these factors make menopausal women reluctant for sexual activities. In some her partner's wish to have regular sex and intercourse but women does not co-operate.

Contrary to this, some percentage of menopausal women make their sexual life much more enjoyable as they minimise the menopausal associated effects by following different therapy (age stated earlier) in their life style. ${ }^{49}$ Secondly the tension of using contraceptives is almost over. It is well established that regular and active involvement in sexual activity enhances the lives of both partners long gaps (abstinence) between the sexual intercourse significantly declines sexual desire of the couples. $^{48}$ The plus point with women is that she can involve herself in sex as and when she wishes to do/ think contrary to man.

If he develope erectable disfunction he cannot complete his sexual act for intercourse process. Long of illnesses develop erectile dysfunction or premature ejaculation like state in men. Variety of other sexual activities like: non genital contact, massages, extended foreplay, sex, masturbation (mutual). Change of positions/dress can certainly make and extend their sexual life and much more enjoyable. ${ }^{47,51}$ If couples stops sexual activities for long period, it is very difficult to regain/return to normal sexual life and also develop the possibility to drive/seek sexual pleasure in other women.

\section{CONCLUSION}

In conclusion, menopause is an essential phase of women's life and its associated effects are bound to experience by her. Menopause can be better managed by meditation yoga HRT herbal approaches under qualified practitioners and it can almost return to premenopausal state (physiology, mentally, emotionally). Sexual life can be much more enjoyable with adequate intake nutritious diet and physical exercises.

Funding: No funding sources Conflict of interest: None declared Ethical approval: Not required

\section{REFERENCES}

1. González JAR, Lemos RV, Filho JC, Varghese A. Overview of the Female Reproductive System. Exercise and Human Reproduction. 2016: 19-44.

2. Wursig B, Perrin W, Wursig B, Thewissen J. Encyclopedia of Marine Mammals. 2nd ed. Netherland: Elsevier; 2008.

3. Haroun HSW. Reproductive cycles in females. Med Crave. 2016;2:2.

4. Richards JS. The Ovarian Cycle. Vitam Horm. 2018;107:1-25.

5. Holesh JE, Bass AN, Lord M. Physiology. Ovulation. Treasure Island, FL: StatPearls Publishing; 2021.

6. Bull JR, Rowland SP, Scherwitzl EB, Scherwitzl R, Danielsson KG, Harper J. Real-world menstrual cycle characteristics of more than 600,000 menstrual cycles. NPJ Digit Med. 2019;2:83.

7. Azis AA, Kurnia N, Bida A. Menstrual Cycle Length in Women Ages 20-30 years in Makassar. Phys Conf Ser. 2018;1028:12019.

8. Wilcox AJ, Dunson D, Baird DD. The timing of the "fertile window" in the menstrual cycle: day specific estimates from a prospective study. BMJ. 2000;321(7271):1259-62.

9. Reed BG, Carr BR. The normal menstrual cycle and the control of ovulation. Endotext. 2015.

10. Ali AM, Ahmed AH, Smail L. Psychological Climacteric Symptoms and Attitudes toward Menopause among Emirati Women. Int J Environ Res Public Health. 2020;17(14):5028.

11. Hajj A, Wardy N, Haidar S, Bourgi D, Haddad ME, Chammas DE, et al. Menopausal symptoms, physical activity level and quality of life of women living in the Mediterranean region. PLoS One. 2020;15(3):230515.

12. Willi J, Süss H, Ehlert U. The Swiss Perimenopause Study - study protocol of a longitudinal prospective study in perimenopausal women. Womens Midlife Health. 2020;6:5.

13. McCarthy M, Raval AP. The peri-menopause in a woman's life: a systemic inflammatory phase that enables later neurodegenerative disease. J Neuroinflammation. 2020;17(1):317.

14. Rodrigues M, Carneiro M. Peri and postmenopausal women in times of coronavirus pandemic. Women Health. 2020;60(10):1079-82.

15. Kulak, David K, Laura TG, Gerson. The etiology of menopause: not just ovarian dysfunction but also a role for the central nervous system. Global Reprod Health. 2018;3(2):8.

16. Santoro N, Crawford SL, Khoudary SR, Allshouse AA, Bowie SA, Finkelstein J, et al. Menstrual Cycle Hormone Changes in Women Traversing Menopause: Study of Women's Health Across the Nation. J Clin Endocrinol Metab. 2017;102(7):2218-29.

17. Surendar R, Durgapriya G, Arthi M, Srikanth. Quality of life among post - menopausal women in rural Puducherry. Int J Public Health Res. 2019;6(3):23494166. 
18. Kalhan M, Singhania K, Choudhary P, Verma S, Kaushal P, Singh T. Prevalence of Menopausal Symptoms and its Effect on Quality of Life among Rural Middle Aged Women (40-60 Years) of Haryana, India. Int J Appl Basic Med Res. 2020;10(3):183-8.

19. Malik E, Sheoran P, Siddiqui A. Health-Promoting Behaviors and Menopausal Symptoms: An Interventional Study in Rural India. J Midlife Health. 2018;9(4):200-6.

20. Du L, Xu B, Huang C, Zhu L, He N. Menopausal Symptoms and Perimenopausal Healthcare-Seeking Behavior in Women Aged 40-60 Years: A Community-Based Cross-Sectional Survey in Shanghai, China. Int J Environ Res Public Health. 2020;17(8):2640.

21. Mohammed FMS, Mohammed SN. Effect of menopausal symptoms on psychological problems among middle-aged women. Egypt Nurs J. 2018;15:292-301.

22. Kim JE, Chang JH, Jeong MJ, Choi J, Park J, Baek C, Shin A, et al. A systematic review and meta-analysis of effects of menopausal hormone therapy on cardiovascular diseases. Sci Rep. 2020;10(1):20631.

23. Cagnacci A, Venier M. The Controversial History of Hormone Replacement Therapy. Medicina (Kaunas). 2019;55(9):602.

24. Academic Committee of the Korean Society of Menopause, Lee SR, Cho MK, Cho YJ, Chun S, Hong $\mathrm{SH}$, et al. The 2020 Menopausal Hormone Therapy Guidelines. J Menopausal Med. 2020;26(2):69-98.

25. MacGregor EA. Migraine, menopause and hormone replacement therapy. Post Reprod Health. 2018;24(1):11-8.

26. Kargozar R, Azizi H, Salari R. A review of effective herbal medicines in controlling menopausal symptoms. Electron Physician. 2017;9(11):5826-33.

27. Baranwal V. Beyond HRT-Ayurveda for Menopause and Associated Aging Problems. Res Gate. 2015.

28. Kahraman C, Zekiye A, Iffet C. The Clinical Importance of Herb-Drug Interactions and Toxicological Risks of Plants and Herbal Products. Intech Open. 2020.

29. Kanitkar A, Nadkar K. Treatment options for menopausal women using ayurveda and aromatherapy 197. Int J Pharm Sci Rev Res. 2014;26(2):197-200.

30. Ghosh D. Quality issues of herbal medicines: internal and external factors. Int J Compl Alt Med. 2018;11.

31. Morkas. Homeopathic Remedies for Menopause Symptoms,2020. Available at: https://homeopathybrisbane.com/homeopathicremedies-for-menopause-symptoms/. Accessed on 1 January 2022.

32. Saffari E, Charandabi MAS, Adibpour M, Mirghafourvand M, Javadzadeh Y. Comparing the effects of Calendula officinalis and clotrimazole on vaginal Candidiasis: A randomized controlled trial. Women Health. 2017;57(10):1145-60.

33. Sikarwar A. Role of homoeopathy in menopause. Int J Homoeop Sci. 2020;4(2):76-84.
34. Lund KS, Siersma V, Brodersen J, Waldorff FB. Efficacy of a standardised acupuncture approach for women with bothersome menopausal symptoms: a pragmatic randomised study in primary care (the ACOM study). BMJ Open. 2019;9(1):23637.

35. Verywell Health. Types and Benefits of Hydrotherapy, 15 Water-Based Therapies Used in Traditional and Alternative Medicine, 2020. Available at: https://www.ve rywellhealth.com/different-types-of-hydrotherapy89993. Accessed on 02 January 2022.

36. Michalak M. Aromatherapy and methods of applying essential oils. Arch Physiother Glob Res. 2018;22(2):25-33.

37. Dagli N, Dagli R, Mahmoud RS, Baroudi K. Essential oils, their therapeutic properties, and implication in dentistry: A review. J Int Soc Prev Community Dent. 2015;5(5):335-40.

38. Eslami J, Ebrahimi A, Hosseinkhani A, Khazaei Z, Darvishi I. The effect of aromatherapy using lavender (Lavandula angustifolia Miller) and citrus aurantium L. extracts to treat anxiety of patients undergoing laparoscopic cholecystectomy: A randomized clinical trial in Iran. Vietnamese J Biomed. 2018;5(3):2096110.

39. Bervoets DC, Luijsterburg PA, Alessie JJ, Buijs MJ, Verhagen AP. Massage therapy has short-term benefits for people with common musculoskeletal disorders compared to no treatment: a systematic review. J Physiother. 2015;61(3):106-16.

40. Taavoni S, Darsareh F, Haghani H. Effect of massage therapy on menopausal symptoms applied by midwife and trained clients: a randomized clinical therapy. European Psych. 2015;30.

41. Bairy L, Adiga S, Bhat P, Bhat R. Prevalence of menopausal symptoms and quality of life after menopause in women from South India. Aust $\mathrm{N}$ Z J Obstet Gynaecol. 2009;49(1):106-9.

42. Kumar SY, Kumar SS, Sharma E. Scientific benefits of yoga: A review, Int J Multidis Res Rev. 2018;3(8):144-8.

43. Cramer H, Lauche R, Langhorst J, Dobos G. Effectiveness of yoga for menopausal symptoms: a systematic review and meta-analysis of randomized controlled trials. Evid Based Complement Alternat Med. 2012;2012:863905.

44. Sung MK, Lee US, Ha NH, Koh E, Yang HJ. A potential association of meditation with menopausal symptoms and blood chemistry in healthy women: A pilot cross-sectional study. Medicine (Baltimore). 2020;99(36):e22048.

45. Shebini MES, Fouad S, Abdel-Moaty M, Hassan AN, Hussein MSA, Essa AH, et al. Dietary supplement for relieving menopausal symptoms in Egyptian perimenopausal women. Bulletin National Res Centre. 2020;44(39).

46. Bailey TG, Cable NT, Aziz N, Atkinson G, Cuthbertson DJ, Low DA, Jones H. Exercise training reduces the acute physiological severity of post- 
menopausal hot flushes. J Physiol. 2016;594(3):65767.

47. Erbil N. Attitudes towards menopause and depression, body image of women during menopause. Alexandria J Med. 2018;54(3):241-6.

48. Kolodziejczak K, Drewelies J, Deeg D, Huisman M, Gerstorf D. Perceived Importance and Enjoyment of Sexuality in Late Midlife: Cohort Differences in the Longitudinal Aging Study Amsterdam (LASA). Springer. 2021;18:625-31.

49. Thornton K, Chervenak J, Neal-Perry G. Menopause and Sexuality. Endocrinol Metab Clin North Am. 2015;44(3):649-61.

50. Cain VS, Johannes CB, Avis NE, Mohr B, Schocken M, Skurnick J, Ory M. Sexual functioning and practices in a multi-ethnic study of midlife women: baseline results from SWAN. J Sex Res. 2003;40(3):266-76.

51. Yafi FA, Jenkins L, Albersen M, Corona G, Isidori AM, Goldfarb S, et al. Erectile dysfunction. Nat Rev Dis Primers. 2016;2:16003.

52. Fiaveh YD, Michael PK, Okyerefo. Femininity, Sexual Positions and Choice. Sagepub. 2019;2(1-2).

Cite this article as: Kumar M, Singh S. Menopause: a new beginning of happy years. Int J Reprod Contracept Obstet Gynecol 2022;11:1009-15. 